\title{
Variations of Lung Function Status in Hypertension and Antihypertensive Medication
}

\author{
Nahar $\mathrm{MN}^{1}$, Begum $\mathrm{S}^{2}$, Ferdousi $\mathrm{S}^{3}$, Sultana $\mathrm{S}^{4}$, Parveen $Z^{5}$, Akhter $\mathrm{T}^{6}$, Habib $\mathrm{T}^{7}$
}

\begin{abstract}
Introduction: Essential hypertension is associated with altered pulmonary function. Antihypertensive medication and lung function are also associated. Amlodipine (calcium channel blocker) and Atenolol (beta blocker) are commonly used antihypertensive drugs.
\end{abstract}

Objective: To evaluate the effects of antihypertensive drugs on lung function status in patients with essential hypertension.

Materials and Methods: This prospective observational study was carried out in the Department of Physiology of Bangabandhu Sheikh Mujib Medical University (BSMMU), Shahbag, Dhaka, from July 2012 to June 2013 on 100 newly diagnosed essential hypertensive patients. Based on prescribed treatment, these study subjects were divided into two groups - B1 and B2. B1 included 50 patients who received amlodipine $5 \mathrm{mg}$ daily and B2 included 50 patients who received atenolol $50 \mathrm{mg}$ daily. Lung function tests were done in both B1 and B2 groups before taking medication, after 3 months of medication and after 6 months of medication. For assessing lung function status, Forced Vital Capacity (FVC), Forced Expiratory Volume in 1st second $\left(\mathrm{FEV}_{1}\right)$ and Peak Expiratory Flow Rate (PEFR) were measured with a computer based Spirometer. Age, sex and BMl matched 50 apparently healthy normotensive subjects were also studied as control (group A). Data were compared among subjects of different groups. For statistical analysis independent sample' $t$ ' test and paired sample 't' test were performed.
Results: Mean FVC, FEV 1 and PEFR were significantly lower in newly diagnosed hypertensive patients in comparison with that of healthy normotensive subjects. Mean FVC, FEV and PEFR were found significantly higher in the group taking amlodipine for 6 months when compared to newly diagnosed hypertensive patients but lower than those of controls. In addition mean FVC and FEV 1 were found significantly lower in the group taking atenolol for 6 months when compared to newly diagnosed hypertensive patients and those of controls.

Conclusion: Reduced lung function occurs in newly diagnosed essential hypertensive patients which improve by treatment with amlodipine but decreases after treatment with atenolol.

Key-words: Newly diagnosed essential hypertensive patients, lung function status, antihypertensive drugs.

\section{Introduction}

Hypertension is an increasingly important public health challenge throughout the world among the cardiovascular diseases ${ }^{1}$. Essential hypertension is the most common form, accounts for $90-95 \%$ of all causes of hypertension ${ }^{2}$. Although several studies observed that high blood pressure has link to multiple clinical outcomes including cardiac, cerebrovascular, renal and eye diseases ${ }^{3}$, a few studies found an association between lung function and hypertension ${ }^{4-10}$. All antihypertensive drugs lower high blood pressure, though drugs from different classes differ in their mechanisms of action. Therefore changes in pulmonary function with chronic

\footnotetext{
1. Maj Mst Nasrin Nahar, MBBS, MD, Assistant Professor of Physiology, AFMC, Dhaka 2. Dr Shelina Begum, MBBS, MPhil, Professor and Chairman of Physiology, BSMMU, Shahbag, Dhaka 3. Dr Sultana Ferdousi, MBBS, MPhil, Associate Professor of Physiology, BSMMU, Shahbag, Dhaka 4. Lt Col Sharmeen Sultana, MBBS, MPhil, Assistant Professor of Physiology, AFMC, Dhaka 5. Lt Col Zinia Parveen, MBBS, MPhil, Assistant Professor of Physiology, AFMC, Dhaka 6. Dr Tunergina Akhter, MBBS, MPhil, Assistant Professor of Physiology, Army Medical College, Bogra 7. Dr Tamanna Habib, MBBS, MD, Assistant Professor of Physiology, Anower Khan Modern Medical College and Hospital, Dhaka.
} 
antihypertensive drugs therapy would be expected to differ depending on the site and mechanism of action of the drugs. Several studies suggested that Calcium channel blockers have no adverse effects on resting airway function in patients with asthma $^{11,12}$. Some studies revealed no significant bronchodilatation 45 minutes after Calcium channel blocker administration in asymptomatic asthma patients $^{13}$. On the otherhand, another study observed improvement of airway resistance, peak expiratory flow rates and $\mathrm{FEV}_{1}$ after one and two hours of Calcium channel blocker administration in patients with bronchial asthma ${ }^{14}$. Few studies revealed that relatively cardioselective agents has been considered contraindicated in patients with asthma or COPD, as it may produce bronchoconstriction and thereby worsen respiratory flows and symptoms in these patients ${ }^{15,16}$. On the other hand, Two systematic reviews of randomized controlled trials revealed that the cardioselective beta blocker has no adverse effects on lung functions in patients with asthma or COPD ${ }^{17,18}$.

Although several investigators observed the effect of amlodipine and atenolol on lung function separately no report compared the effect of amlodipine and atenolol on lung function in newly diagnosed hypertensive patients. Therefore this study aimed to evaluate the lung function in untreated hypertensive patients and compare the effect of amlodipine and atenolol on lung function.

\section{Materials and Methods}

This prospective observational study was carried out in the Department of Physiology of Bangabandhu Sheikh Mujib Medical University (BSMMU), Shahbag, Dhaka, from July 2012 to June 2013. Hundred newly diagnosed hypertensive patients aged 30-55 years were selected as study group. Age, sex and BMI matched 50 apparently healthy normotensive subjects were also studied as control (group A). Based on treatment, these study subjects were divided into two groups; B1 and B2. B1 included 50 patients who received amlodipine $5 \mathrm{mg}$ daily and B2 included 50 patients who received atenolol $50 \mathrm{mg}$ daily. Lung function tests were done in both B1 and B2 groups before taking medication, after 3 months of medication and after 6 months of medication. Basing on the duration of the treatment group $\mathrm{B} 1$ was named as $\mathrm{B} 1_{\mathrm{a}}$ (newly diagnosed hyper- tensive patients before treatment), $\mathrm{B} 1_{\mathrm{b}}$ (after 3 months of medication with amlodipine) and $\mathrm{B} 1_{\mathrm{C}}$ (after 6 months of medication with amlodipine). Similarly subjects of group B2 were named as B2a (newly diagnosed hypertensive patients before treatment), B2 ${ }_{b}$ (after 3 months of medication with atenolol) and $\mathrm{B}_{\mathrm{c}}$ (after 6 months of medication with atenolol). These patients were selected from the Out Patient Department of Cardiology, BSMMU.

Subjects with history of acute or chronic lung and chest wall disease e.g. pneumonia, tuberculosis, asthma, COPD, malignancy etc, history of coronary heart disease, diabetes mellitus, alcohol/tobacco users and smokers were excluded from the study. After random selection of the subjects a detail personal, medical, family, socioeconomic, occupational and drug history were recorded in a preformed questionnaire and thorough physical examinations were done and documented. For the assessment of lung function FVC, FEV 1 and PEFR were measured with a computer based Spirometer.

Then all the patients were requested to attend the Department of Physiology of BSMMU, again after 3 months and after 6 months of antihypertensive medication, to have the assessment of the above mentioned study variables. For statistical analysis independent sample 't' test and paired sample't' test were performed by using SPSS (Statistical Package for Social Sciences) for windows version 16.0 as applicable. $\mathrm{P}$ value $<0.05$ was accepted as level of significance.

\section{Results}

The mean of the percentages of predicted values of FVC, FEV 1 and PEFR were significantly lower in group $B 1_{a}, B 1_{b}$ and $B 1_{c}$ respectively than those of control. In addition, the mean percentage of predicted values of FVC, FEV 1 and PEFR were significantly increased in group $B 1_{b}$ and $B 1_{c}$ in comparison to their corresponding base line values of group B1 ${ }_{a}$ (Table-I).

Table-I: Percentages of predicted values of FVC, $F_{1}$ and PEFR in different groups $(n=100)$

\begin{tabular}{|c|c|c|c|c}
\hline Parameters & Group A $(\mathrm{n}=50)$ & B1 $_{\mathbf{a}}(\mathrm{n}=50)$ & B1 $_{b}$ & B1 $_{\mathbf{c}}$ \\
\hline FVC (L) & $88.9 \pm 0.827$ & $73.9 \pm 1.037$ & $76.28 \pm 0.960$ & $78.12 \pm 0$. \\
\hline FEV $_{1}(\mathrm{~L})$ & $90.62 \pm 0.772$ & $79.38 \pm 1.157$ & $81.08 \pm 1.151$ & $83.3 \pm 1.0$ \\
\hline PEFR $(\mathrm{L} / \mathrm{s})$ & $78.38 \pm 1.373$ & $72.96 \pm 1.289$ & $73.5 \pm 1.235$ & $75.6 \pm 1.3$ \\
\hline
\end{tabular}


Statistical analysis

\begin{tabular}{|c|c|c|c|}
\hline \multirow{2}{*}{ Groups } & \multicolumn{3}{|c|}{ p value } \\
\cline { 2 - 4 } & $\mathrm{FVC}$ & $\mathrm{FEV}_{1}$ & PEFR \\
\hline $\mathrm{A}$ vs B1 $1_{\mathrm{a}}{ }^{\varphi}$ & $0.000^{* * *}$ & $0.000^{* * *}$ & $0.005^{* *}$ \\
\hline $\mathrm{A}$ vs B1 $1^{\varphi}$ & $0.000^{* * *}$ & $0.000^{* * *}$ & $0.010^{*}$ \\
\hline $\mathrm{A}$ vs B1 $1_{\mathrm{c}}{ }^{\varphi}$ & $0.000^{* * *}$ & $0.000^{* * *}$ & $0.150 \mathrm{~ns}$ \\
\hline $\mathrm{B} 1_{\mathrm{a}} \mathrm{vs} \mathrm{B}_{\mathrm{b}}{ }^{\Omega}$ & $0.000^{* * *}$ & $0.016^{*}$ & $0.465 \mathrm{~ns}$ \\
\hline $\mathrm{B} 1_{\mathrm{b}} \mathrm{vs} \mathrm{B}_{\mathrm{c}}{ }^{\Omega}$ & $0.000^{* * *}$ & $0.000^{* * *}$ & $0.055 \mathrm{~ns}$ \\
\hline $\mathrm{B} 1_{\mathrm{a}} \mathrm{Vs} \mathrm{B}_{\mathrm{c}}{ }^{\Omega}$ & $0.000^{* * *}$ & $0.000^{* * *}$ & $0.033^{*}$ \\
\hline
\end{tabular}

Data were expressed as mean \pm SD.

$\varphi=$ independent sample 't' test, $\Omega=$ Paired sample 't' test Group A: Apparently healthy subjects (control group) Group $B 1_{\mathrm{a}}$ : Newly diagnosed hypertensive patients before treatment Group B1 : After 3 month's treatment with amlodipine Group B1 $1_{c}$ : After 6 month's treatment with amlodipine ${ }^{* * *}:$ Significant $(p \leq 0.001),{ }^{* *}:$ Significant $(p \leq 0.01),{ }^{*}:$ Significant $(p \leq 0.05)$ Ns:Nonsignificant, n:Number

The mean of the percentages of predicted values of FVC, FEV 1 and PEFR were significantly lower in group $B 2_{a}, B 2_{b}$ and $B 2_{c}$ respectively than those of control. In addition, the mean percentage of predicted values of $F V C$ and $F E V_{1}$ were significantly decreased in group $\mathrm{B} 2_{\mathrm{b}}$ and $\mathrm{B} 2_{\mathrm{c}}$ in comparison to their corresponding base line value $\mathrm{B} 1_{\mathrm{a}}$. But the mean percentage of predicted value of PEFR was nonsignificantly increased in group $B 2_{b}$ and $B 2_{c}$ in comparison to their corresponding base line values of group B2 ${ }_{\mathrm{a}}$ (Table-II).

Table-II: Percentages of predicted values of FVC, $\mathrm{FEV}_{1}$ and PEFR in different groups $(\mathrm{n}=100)$

\begin{tabular}{|c|c|c|c|c|}
\hline Parameters & $\mathbf{A}(\mathbf{n}=\mathbf{5 0})$ & $\mathbf{B}_{\mathbf{a}}(\mathbf{n}=\mathbf{5 0})$ & $\mathbf{B}_{\mathbf{b}}$ & $\mathbf{B}_{\mathbf{c}}$ \\
\hline FVC $(\mathrm{L})$ & $88.9 \pm 0.827$ & $74.72 \pm 0.786$ & $72.84 \pm 0.997$ & $71.42 \pm 1.028$ \\
\hline FEV1 (L) & $90.62 \pm 0.772$ & $79.04 \pm 1.079$ & $76.88 \pm 1.248$ & $75.62 \pm 1.298$ \\
\hline PEFR (L/s) & $78.38 \pm 1.373$ & $74.36 \pm 1.444$ & $75.28 \pm 1.353$ & $76.6 \pm 1.302$ \\
\hline
\end{tabular}

Statistical analysis

\begin{tabular}{|c|c|c|c|}
\hline \multirow{2}{*}{ Groups } & \multicolumn{3}{|c|}{ p value } \\
\hline & FVC & $\mathrm{FEV}_{1}$ & PEFR \\
\hline A vs B2 ${ }^{\varphi}$ & $0.000 * * *$ & $0.000^{* * *}$ & $0.046^{*}$ \\
\hline A vs B2 ${ }^{\varphi}$ & $0.000 * * *$ & $0.000^{* * *}$ & $0.111 \mathrm{~ns}$ \\
\hline $\mathrm{A}$ vs B $2_{\mathrm{c}^{\varphi}}$ & $0.000^{* * *}$ & $0.000^{* * *}$ & $0.349 \mathrm{~ns}$ \\
\hline $\mathrm{B} 2_{\mathrm{a}}$ vs B2${ }_{\mathrm{b}}{ }^{\Omega}$ & $0.000^{* * *}$ & $0.000 * * *$ & $0.317 \mathrm{~ns}$ \\
\hline $\mathrm{B} 2_{\mathrm{b}}$ vs B2 ${ }_{\mathrm{c}}{ }^{\Omega}$ & $0.000^{* * *}$ & $0.042^{*}$ & $0.154 \mathrm{~ns}$ \\
\hline$B 2_{a}$ vs B2 ${ }_{c}{ }^{\Omega}$ & $0.000^{* * *}$ & $0.000^{* * *}$ & $0.035^{*}$ \\
\hline
\end{tabular}

Data were expressed as mean $\pm S D$

$\varphi=$ independent sample 't' test, $\Omega=$ Paired sample 't' test Group A: Apparently healthy subjects (control group) Group B2: Newly diagnosed hypertensive patients before treatment Group B2 : After 3 month's treatment with atenolol Group B2: After 6 month's treatment with atenolol ${ }^{* * *}:$ Significant $(p \leq 0.001),{ }^{* *}:$ Significant $(p \leq 0.01),{ }^{*}:$ Significant $(p \leq 0.05)$ Ns:Nonsignificant, n:Number

\section{Discussion}

In the present study, values of the lung function parameters FVC (L) 88.9 $\pm 0.827, \mathrm{FEV}_{1}$ (L) $90.62 \pm 0.772$ and PEFR (L/s) 78.38 \pm 1.373 in healthy normotensive group were almost similar with the study of Selby et $\mathrm{al}^{5}$. The mean of the percentages of predicted values of FVC $(73.9 \pm 1.037,74.72 \pm 0.786)$, FEV $_{1}(79.38 \pm 1.157$, $79.04 \pm 1.079)$ and PEFR $(72.96 \pm 1.289,74.36 \pm 1.444)$ were significantly $(p \leq 0.001)$ lower in newly diagnosed hypertensive patients than those of apparently healthy subjects. Lingarde and Schroeder et $\mathrm{al}^{19,20}$ found significantly $(p \leq 0.01)$ lower FVC in hypertensive patients. Again in this study the lower values of the mean percentages of predicted values of FVC and FEV1 were significantly $(p \leq 0.01)$ improved after 3 months (FVC-76.28 $\left.\pm 0.960, \mathrm{FEV}_{1}-81.08 \pm 1.151\right)$ and 6 months (FVC-78.12 $\pm 0.970, F_{1}-83.3 \pm 1.041$ ) treatment with amlodipine. The lower values of these two parameters were further reduced after 3 months (FVC-72.84 \pm 0.997 , FEV1-76.88 \pm 1.248 ) and 6 months (FVC-71.42 $\pm 1.028, F_{1}-75.62 \pm 1.298$ ) treatment with atenolol. Van Zyl and Lawrence et al have revealed lower FVC (72.49) and FEV 1 (76.26) in hypertensive patients after using cardioselective beta blocker ${ }^{16,21}$. In addition the lower values of PEFR was non-significantly improved after 3 months and significantly improved after 6 months treatment with amlodipine and atenolol.

Researchers suggested that the decrement of different ventilatory variables in essential hypertension may be associated with early left ventricular hypertrophy and moderately left ventricular dysfunction which may increase left atrial pressure. As a consequence, an elevation of pulmonary arterial pressure and interstitial oedema in the lung leading to decreased compliance of the lung and mild restrictive disease ${ }^{4,5,10}$.

Different studies suggested various mechanisms for the improvement of lung function status in hypertensive patients after treatment with amlodipine. Calcium causes smooth muscle contraction, degranulation of mast cells and secretion of mucous from different cells in the airway epithelium ${ }^{22}$. Calcium channel blockers are vasodilators and in hypertension it inhibits calcium influx into arterial smooth muscle cells ${ }^{23}$. It has been suggested that Calcium channel blocker may reduce bronchoconstriction by inhibition of contraction of bronchial smooth muscle and release of mediators from mast cells or polymorphonuclear neutrophils in asthma patients ${ }^{13}$. 
Different researchers suggested various mechanisms for the decrement of lung function status in hypertensive patients after treatment with atenolol. In the respiratory system, Beta 2 adrenergic receptors (B2-ARs) represent the $70 \%$ of all Beta Adrenergic Receptor ( $\beta-A R)$, with the Beta 1 Adrenergic Receptors ( $\beta 1$-ARs) accounting for the remainder. As a consequence, the use of a selective B1-AR antagonist may not involve only for vascular effect ${ }^{24}$. It has been suggested that bronchodilatation is mediated by autonomic beta-adrenoceptors, the dominant subtype ${ }^{25}$ being $\beta 2$. Beta-blocker cardioselectivity is dose dependent, with competitive antagonism of both $\beta 1$ and $\beta 2$ adrenoceptors at higher plasma concentrations. Therefore with higher doses of cardioselective beta-blockers, $\beta 2$ receptor blockade may cause minor increases in airflow obstruction possibly through unopposed parasympathetic bronchoconstriction ${ }^{26}$. Furthermore, beta-agonist improved the performance of skeletal muscles and also positively affect respiratory muscle strength $^{27,28,29}$. Therefore Beta blocker medication may result in a slight reduction of expiratory muscle strength causing a proportional decrease of $\mathrm{FEV}_{1}$ and $\mathrm{FVC}^{10}$. The exact mechanisms involved for the decrement of lung functions in hypertension and improvement after treatment with amlodipine but not with atenolol in hypertensive groups of present study could not be elucidated from this type of study. However, it is assumed that all the above mentioned mechanisms may influence the degree of deterioration of these variables in hypertension patients and improvement after treatment with amlodipine but not with atenolol.

\section{Conclusion}

The ventilatory variables decrease in newly diagnosed patients with hypertension and lung function status improves after treatment with amlodipine but further decreases after treatment with atenolol. Apart from the suggested mechanism by several researchers these decrement may be associated with silent pulmonary disorders without presenting any pulmonary symptoms.

\section{References}

1. Kearney PM, Whelton M, Reynolds $\mathrm{K}$ et al. Worldwide prevalence of hypertension: A systematic review. J Hypertens 2004; 22(1):11-9.

2. Carretero OA, Oparil S. Essential hypertension. Part I: definition and etiology. Circulation 2000; 101(3):329-35.
3. Flack JM, Peters R, Shafi $T$ et al. Prevention of hypertension and its complications: theoretical basis and guidelines for treatment. J Am Soc Nephrol 2003; 14:92-8.

4. Sparrow D, Weiss ST, Vokonas PS et al. Forced vital capacity and the risk of hypertension. The normative aging study. Am J Epidemiol 1988; 127(4):734-41.

5. Selby JV, Friedman GD, Queensberry CP Jr. Precursors of essential hypertension: Pulmonary function, heart rate, uric acid, serum cholesterol and other serum chemistries. Am J Epidemiol 1989; 131(6):1017-27.

6. Enright PL, Kronmal RA, Smith VE et al. Reduced vital capacity in elderly persons with hypertension, coronary heart disease or left ventricular hypertrophy: The cardiovascular health study. Chest 1995; 107(1):28-35.

7. Wu Y, Vollmer WM, Buist AS et al. Relationship between lung function and blood pressure in Chinese men and women of Beijing and Guangzhou. Int J Epidemiol 1998; 27:49-56.

8. Engstrom G, Wollmar P, Valind $S$ et al. Blood pressure increases between 55 and 68 years of age is inversely related to lung function: longitudinal results from the cohort study Men born in 1914. J Hypertens 2001; 19: 1203-8.

9. Margretardottir OB, Thorleifsson SJ, Gudmundsson G, et al. Hypertension, systemic inflammation and body weight in relation to lung function impairment: An epidemiological study. COPD 2009; 6(4):250-5.

10. Schnabel E, Nowak D, Brasche S et al. Association between lung function, hypertension and blood pressure medication. Respiratory Medicine 2011; 105:727-33.

11. Williams DO, Barnes PJ, Vickers HP et al. Effect of nifedipine on bronchomotor tone and histamine reactivity in asthma. Br Med J 1981; 283:348.

12. Gonzalez JM, Monice RC, Bloom K et al. Inhibition of airway reactivity by nifedipine in patients with coronary artery disease. Am Rev Respir Dis 1983; 127(2):155-7.

13. Cerrina J, Denjean A, Alexandre G et al. Inhibition of exercise induced asthma by a calcium antagonist, nifedipine. Am Rev Respir Dis 1981; 123(2):156-60.

14. Patakas D, Vlachoianni E, Tsara V et al. Nifedipine in bronchial asthma. J Allergy Clin Immunol 1983; 72(3): 269-73.

15. Doshan HD, Rosenthal RR, Brown R, et al. Celiprolol, atenolol, and propranolol: A comparison of pulmonary effects in asthmatics patients. J Cardiovas Pharmacol 1986; 8(Suppl 4):S105-S8. 
16. Van Zyl AL, Jennings AA, Bateman ED et al. Comparison of respiratory effects of two cardioselective beta-blockers, celiprolol and atenolol, in asthmatics with mild to moderate hypertension. Chest 1989; 95(1):209-13.

17. Salpeter S, Ormiston T, Salpeter E. Cardioselective beta-blockers for reversible airway disease. Cochrane Database Syst Rev 2002; 1:CD002992.

18. Salpeter S, Ormiston T, Salpeter E. Cardioselective beta-blockers for chronic obstructive pulmonary disease. Cochrane Database Syst Rev 2005; 1:CD003566.

19. Lindgarde F, Furo M, Ljung BO. A longitudinal study on the significance of environmental and individual factors associated with the development of essential hypertension. J Epidemiol Comm Health 1987; 41:220-6.

20. Schroeder EB, Welch VL, Couper D et al. Lung function and incident coronary heart disease. Am J Epidemiol 2003; 158(12):1171-81.

21. Lawrence DS, Sahay JN, Chatterjee SS et al. $\beta$-blockers in asthma. Drugs 1983; 25:232-6.

22. Lofdahl GC. Antihypertensive drugs and airway function with special reference to calcium channel blockade. Journal of cardiovascular pharmacology 1989; 14(10):S40-S51.
23. Katzung BG, Masters SB, Trevor AJ. Basic and clinical pharmacology. 11th ed. New Delhi: Tata McGraw Hill education private limited 2009. p181.

24. Antonellilnc, Pedone C. Respiratory effects of beta adrenergic receptor blockers. Curr Med Chem 2007; 14(10):1121-8.

25. Guyton AC, Hall JE. Textbook of Medical Physiology. 12th ed. Singapore: Saunders Elsevier 2011; p173, 230-1, 465-526.

26. Hawkins et al. Bisoprolol in patients with heart failure and moderate to severe chronic obstructive pulmonary disease: A randomized controlled trial. European Journal of Heart Failure 2009; 11:684-90.

27. Martineau L, Horan MA, Rothwell NJ et al. Salbutamol, a beta 2-adrenocrptor agonist, increases skeletal muscle strength in young men. ClinSci (London) 1992; 83(5):615-21.

28. Grimm DR, Schilero GJ, Spungen AM et al. Salmeterol improves pulmonary function in persons with tetraplegia. Lung 2006; 184 (6):335-9.

29. Angulo M, Taranto E, Soto JP et al. Salbutamol improves diaphragmatic contractility in chronic airway obstruction. Arch Bronconeumol 2009; 45(5):230-4. 